\title{
Sargramostim Plasmid DNA Pancreatic Tumor Cell Vaccine
}

National Cancer Institute

\section{Source}

National Cancer Institute. Sargramostim Plasmid DNA Pancreatic T umor Cell Vaccine.

NCl Thesaurus. Code C2445.

A whole cell vaccine comprised of irradiated allogenic pancreatic tumor cells transfected with a plasmid DNA encoding human sargramostim (GM-CSF). Vaccination results in expression of GM-CSF, which induces proliferation and differentiation of hematopoietic lineage cells as well as stimulating macrophage and dendritic cell functions in antigen presentation and antitumor cell-mediated immunity. Furthermore, administration of this pancreatic tumor cell vaccine may elicit a cytotoxic $T$ lymphocyte $(C T L)$ response against similar host tumor cells, resulting in decreased tumor growth. 